\title{
Nursing Leadership in Healthcare: The Impact of Effective Nurse Leadership on Quality Healthcare Outcomes
}

\section{Udo Orukwowu}

\author{
Department of Nursing Sciences, Faculty of Basic Medical Sciences, College of Medical Sciences, Rivers State University,
} Nigeria.

Correspondence: udocd27@gmail.com; Phone: +2349060039098

\begin{abstract}
Leadership in nursing is needed in all levels of healthcare to ensure the delivery of excellence and quality nursing care. Sadly, the concept and impact of nursing leadership is often neglected in the healthcare system, especially in the aspect of general decision-making for the overall management of the healthcare system. This article is focused on the review of literature related to nursing leadership as an influential factor to better healthcare outcomes. This review took into account the concept of effective nurse leadership, the theoretical perspectives, competencies and general impacts on healthcare outcomes. From the study, it was noted that for effective leadership, nurses are to be enlightened on the expected leadership qualities for building relationships among nurses, interdisciplinary teams of the nursing profession and patients. Some leadership qualities identified include appearance, self-confidence, self-awareness, motivation, empathy, honesty, vision and purpose, integrity, emotional intelligence, social skills and abilities, commitment and passion. Others are humbleness, creativity and innovation, accountability, delegation, resilience, empowerment and teamwork. Despite the simplicity of the subject, there is a need for further research in this area to reinforce the implementation of nurse leaders experience in the general healthcare setting for efficient care delivery.
\end{abstract}

Keywords: $\quad$ Leadership, Leadership qualities, Nurse leadership, Nurse, Healthcare outcome

\section{Article History}

Received: 22 Jan 2022

Accepted: 10 Feb 2022

Published: 14 Feb 2022

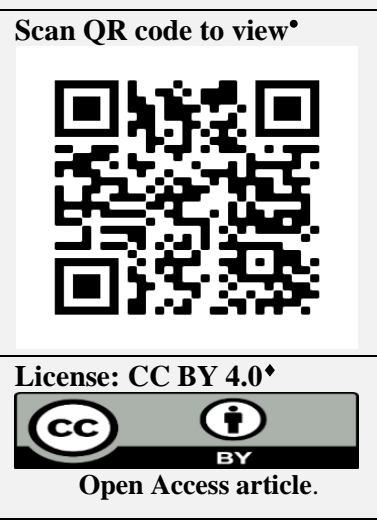

How to cite this paper: Orukwowu, U. (2022). The Impact of Effective Nurse Leadership on Quality Healthcare Outcomes. IPS Interdisciplinary Journal of Social Sciences, 1(1), 1-6. https://doi.org/10.54117/iijss.v1i1.1

\begin{abstract}
1. Introduction
The concept of leadership has been directed to reflect different approaches in different fields of practice, as a result, the definition of leadership has been made to have different meanings to different professions (Ercretin and Utin, 2012; Reed et al. 2019). However, Greenberg (2013) and Mendenhall et al. (2013) emphasized that leadership as a phenomenon does not have a universally agreed definition. In their argument, they pointed out that the various definitions given to leadership are based on concepts such as processes of social impacts and groups, behaviours and characteristics of individuals, relationship exchange roles, patterns of interactions, personality traits, as well as strategies of achieving the goals and objectives of an organisation.
\end{abstract}

Moreover, in conceptualising leadership, Northouse (2012:1) explained leadership as the "process whereby an individual influences a group of persons to achieve a common goal". In terms of leadership as a process, leadership is seen as a strategy whereby the leader affects the followers, and also be affected by his/her followers, making it a transactional event (Todnem and Burnes, 2013). Additionally, leadership involves "influencing followers" and is characterized by the leader being able to affect and influence their followers effectively (Northouse, 2012; Komives et al., 2013).

According to Ercetin and Utin (2012), leadership is driven by organisational objectives. However, Mendenhall et al. (2013) opposed that effective leadership is influenced by the application of effective leadership styles to suit every situation. Accordingly, Igbal (2011) listed the styles of leadership as autocratic, democratic, laissez-faire and transformational. But he indicated that the effectiveness in application brings about organisational success when the required targets are met at the right time. Although, positive mindsets are important in terms of applying the required style of leadership (Randall et al., 2011). However, Adeniyi (2010) advocated that the paramount focus of every leader should be on pursuing a turning vision and effective leadership thereby accomplishing organisational goals and objectives.

Additionally, Adeniyi (2010) indicated that the characteristics of a leader impact his or her effectiveness and how their followers are being influenced. This makes it possible for followers to cling to leaders that are after the welfare of the workers, enhancing the commitment of the workforce to work towards the achievement of the organisational goals (Stanfield, 2009). Consequently, Passmore (2010), highlighted that leaders are followed and respected by their followers because they care for others and are trusted by their subordinates, they are consistent and do not slack in their leadership traits, they are committed to working, they are efficient, they apply their skills appropriately and are competent and knowledgeable enough in their professional practice. Therefore, several authors argued that the efficiency and effectiveness of leadership is influenced by the leader's skills, personality, character and integrity (Passmore, 2010; Halpern and Cheung, 2011; Komives et al., 2013; Mendenhall et al., 2013). 


\section{Leadership Framework}

Over the years, leadership has been given great attention by researchers and professionals, as a result, diverse theories have been promulgated to the development of leadership as a concept (Northouse, 2012). To support this, Foster et al. (2012) emphasized that there has been a great evolution in leadership and theoretical perspectives of leadership. However, the act of leadership is an essential service in all levels of any organisation to get things done in a proper and efficient manner (Bischoff, 2010). To attain the required height in leadership in all levels of leadership of any type of organisation, there have been varied theoretical approaches explaining leadership processes and their complexities to enhance effective leadership processes (Winkler, 2011).

Daft (2008) and Bolden et al. (2011) considered the trait approach to leadership as what makes a good leader. According to them, the success of leadership is immersed in the personal traits of the leader. They further indicated that these traits comprise appearance, self-confidence, honesty and intelligence. According to Colbert et al. (2012), the traits approach is basically for those that seem to have leadership attributes as in-born which on the other hand makes leadership natural in them. However, in Daft's argument, there was a weak relationship existing between individual personality traits and success in leadership, therefore, leadership success does not necessarily depend on a leader to be genetically endowed (Daft, 2008). Nevertheless (Bolden et al., 2011; Augustsson and Boström, 2012) emphasized on his research regarding leadership ability to be attributed to personality traits such as interpersonal skills, initiative, self-confidence, general intelligence, personality integrity, and drive for responsibility.

Moreover, Bolden et al. (2011) argued that leadership skills and qualities could be learnt to achieve the desired outcome. According to Bolden, research has proven learnt leadership skills to bring about the desired outcome in several instances. In support of this, Colbert et al. (2012) added that an individual must not exhibit leadership qualities to be a good leader since leadership skills can be learned. On the other hand, Dinh and Lord (2012) affirmed that a leader with leadership personality traits and who has attained a leadership qualification makes a better leader incorporating personal traits and learned qualities. He added that these types of leaders have been substantiated as being more effective and efficient, exceptional in their performances, gained popularity due to their self-confidence, sociability and fluency of speech. As a result, they desire to persist and excel against any obstacle and challenges that may arise in the processes of leadership. On the other hand, Giltinane (2013) argued that the effectiveness of the leadership process is the effective application of leadership skills in different situations to achieve the desired result.

Similarly, contingency theory is another approach in the process of leadership that has been given recognition (Daft, 2008). The contingency theory is concerned with several other environmental factors that might influence the outcomes of leadership as much as the application of styles of leadership. However, the behaviour of the leader is highly considered in this theory. This is a result of applying different patterns of effective behaviour to different situations (Comack, 2012). According to Kelly (2013), other theories are included in this contingency approach which are the situational theory, path-goal theory, Fielder's contingency theory, and substitute ideas for leadership.

Hersey, Blanchard, and Johnson's situational theory of leadership (2008) deals with the readiness of the followers which is considered as a factor that determines the applicable style of leadership as well as relationship behaviour and task behaviour. Furthermore, in the situational theory, there are other four styles of leadership attributed to it such as telling leadership style which involves low relationship behaviour and high task behaviour; selling leadership style consisting of high relationship style and a high task; participatory leadership style concerned with high relationship style and a low task; and delegating leadership style which entails low relationship style and a low task (Lussier and Achua, 2013). Accordingly, a leadership style is selected among the four styles of leadership for a situation according to the readiness and maturity of the followers (Kelly, 2013). For instance; in telling leadership style, roles and tasks of the followers are being defined and closely supervised by the leader, optimally, there is one-way communication in this style of leadership where the leader makes decisions and announce to the followers without consulting anyone (Lussier and Achua, 2013). Conversely, in the selling leadership style, there is two-way communication, leaders seeking suggestions and ideas from their followers (Kelly, 2013). However, the leaders still decide and define the roles and tasks of the followers (Lussier and Achua, 2013). In terms of participatory leadership style, followers are given the authority by the leader to make daily decisions such as allocating tasks and the followers have the controls (Kelly, 2013). However, the leader takes part and facilitates how the tasks are carried out. Similarly, in delegating leadership, the followers still control and the leaders participate in the decision making (Lussier and Achua, 2013; Kelly, 2013).

In terms of Path-Goal Theory (Robert House, 1971), motivating followers is paramount for the leaders in the intent of influencing the accomplishment of organisational goals. Similarly, the path-goal approach is also concerned with four leadership styles for leadership situations such as supportive, directive, achievement-oriented or participative. According to Kelly (2013), in the directive leadership style, the leader focuses on how the job will be done successfully with his or her directives and authority. The supportive leadership style is concerned with the leader providing attention, interest and encouragement (Greenberg, 2013). Basically, the supportive leadership style is relationship-oriented (Lussier and Achua, 2013). However, followers are involved in the decision-making process by the leader in the participative style of leadership (Northouse, 2010). Furthermore, direction, structure, high support is provided by the leader through behaviour consideration in an achievement-oriented style of leadership (Kelly, 2013). Essentially, in the path-goal approach to leadership, followers' situational characteristics is being matched with the applicable leadership style to enhance motivation, thereby ensuring goal achievements (Kelly, 2013).

Furthermore, Fielder's (1967) Contingency Theory is another approach among the contingency approaches to leadership. This aspect of the contingency approach is concerned with the effectiveness of leadership (Kelly, 2013). According to Kelly, the interaction of the leader's personality and the situational needs determines the directions of the leader's behaviour. However, the degree of structure of tasks, the relationship of the leader and member, as well as the position of power of the leader affects the situational needs and how favourable situations will be (Kelly, 2013). In addition, the Substitute for Leadership aims towards the situational variables that influence both the behaviours of the leader as well as the followers (Hersey et al., 2008). These variables have been identified as the characteristics of the followers where there is a routine way structured to carry out tasks; giving feedback of job satisfaction among followers; adhering to organisational rules and low power position (Hersey et al., 2008). Typically, nurses and other healthcare workers do not need the supervision and direction of their leaders to perform their daily tasks (Comack, 2012). Therefore, the experiences and knowledge acquired by the followers serve as substitutes to leadership. Again, another leadership behaviour substitute for these followers is the intrinsic job satisfaction emerging from the job they are carrying out daily (Kelly, 2013).

In addition, Transformational Leadership Theory (Burns, 1978) is another approach to leadership that has currently received great attention as a kind of leadership where the follower's potentials are being recognised (Vinkenburg et al., 2011; Khan et al., 2020). According to Cummings (2011), transformational leadership is referred to as the process whereby leaders and their followers heave each other to a greater level of morality and motivation. Basically, transformational leadership theory is reliant on the inspiration of getting others empowered to participate in working together towards a shared purpose to pursue and achieve a vision (Kelly, 2013). However, the leader and the followers are fully involved and influenced to greater levels of conduct to achieve transformation. In transformational leadership, values are the driving factor that makes the leader motivate and empower their followers to contribute to the organisational system by behaving in agreement with those values, and the provision of visions that will reflect mutual or common values. Wong and Cummings (2009) argued that in this type of leadership, people are committed to action, converting followers to become potential leaders, also converting the leaders to become agents of change. Moreover, 
Duyulu and Kublay (2011) accentuated that transformational leadership theory makes leaders to become agents of change, driven by values, lifelong learners, courageous, visionaries, and giving solutions to complex situations thereby making themselves effective leaders undergoing transformation.

Furthermore, change and innovation are the core business of transformational leadership in every organisation (Wong and Cummings, 2009; Doody and Doody, 2012). Therefore for leaders to bring change and innovation, they reinforce the shared vision based on the organisational values to inspire and motivate followers, ensuring advancement and growth (Bondas, 2012). Additionally, Northouse (2010) and Giltinane (2013) argued that committing to a vision, committing to action and selfless interest in transformational leadership is guided by being inspired and empowered, which brings the expected change. Therefore, transformational theory strongly advocates for inspiring and empowering relationships between the follower and leader to encourage them to be committed to working toward their shared values (Wang et al., 2012). It has been revealed by several researchers that nurses have adopted the transformation theory due to the values accorded to it (Kelly, 2008). This has made them have good relationships between them as nurses and between the nurse leaders and other nurses enhancing commitment that leads to high productivity in the healthcare setting (Doody and Doody, 2012; Giltinane, 2013)

\section{Leadership in Nursing/Healthcare System}

The demand for nursing services is on the increase, as a result, effective nursing leadership is also highly needed for the provision of quality and evidence-based care in a multicultural setting (Buscer et al., 2009; Eneh et al., 2012). The need for effective leadership has triggered several types of research to explore strategic roles, measurement of performance as well as how leadership paradigms will be employed to improve and increase performance in the healthcare setting. Cummings et al. (2010) acclaimed that positive impacts on nursing work have been accorded to nursing leadership practice. However, nurse leaders have been faced with challenges and difficulties in processes of administration and clinical technologies due to their complexity; these have also made nurses very unique and valuable in devising solutions to the problems that emanate due to leadership processes. Significantly, Eneh et al. (2012) identified that nurses apply their knowledge and experiences accordingly in their nursing practise to meet the organisational goals of the healthcare systems.

In healthcare, leadership is regarded as an agent of change (Bjarnason and Ann, 2011). Hence, nurse leaders are striving in ways of transforming the nursing workforce in the performance of those duties that will transform. However, the workforce is being motivated influenced and empowered to perform their full potential. Nevertheless, the transformational nurse leader is required to strategies methods of supporting nurses to attain a greater level of knowledge enhancement and skill development thereby working toward change in the organisation. In this regard, Buscer et al. (2009) hypothesised that knowledge acquisition influences bette performance thereby bringing about change in the attitude, behaviour and belief of an individual to act in a way of achieving a shared value (Buscer et al., 2009; Cummings et al., 2010; Eneh et al., 2012)

Furthermore, leadership in nursing is needed in all levels of healthcare practice to enable them to create strategies that will ensure the delivery of excellence and quality nursing care (Buykh et al., 2010). However, Newton (2009), Cummings et al. (2009) and Bish et al. (2012) emphasized nurse leaders should be in the forefront of all levels of the healthcare system with the best possible evidence-based practice with the ability to take the nursing profession to a higher level by providing effective and efficient care; thereby meeting the complexity and diversity needs across healthcare setting. However, Misener et al. (2008) and Perry et al. (2009) identified one of the problems that exist that nurse leaders need to address as relationship issues, to ensure good relationships within nurses and other health practitioners, and between nurses and clients/patients, to ensure effective care within healthcare professionals and as well give patients good experience by keeping them in the centre of their treatment.
Conversely, there is a need for contemporary leadership in the present healthcare systems due to some failures that have been noticed within nursing leaders in maintaining standardised and quality care (Perry et al., 2009; Bish et al., 2012). However, the research carried out by Bish et al. (2012) and Porter-O'Grady and Malloch (2012) proved that nurses are lacking in different areas due to some challenges they are facing especially in nursing practice in rural areas. Therefore, nurse leaders need to be equipped with the necessary knowledge and skills to face the challenge of the contemporary issues in nursing leadership thereby developing strategies to ensure adequate healthcare reforms to enhance the provision of excellent service delivery in all healthcare settings (Newton, 2009).

In addition, nursing leadership in Nigeria has been on evolution shifting from one stage to the other with the notion of improving all levels of healthcare practice (Adeniyi, 2010). In Nigeria, being a nurse leader is all about making effective decisions, hard work, enthusiasm, and dedication. Mcdikkoh (2010) proclaimed that Nigerian nurse leaders are striving and ensuring that followers are motivated, inspired and communicated with the development in nursing practice, for the followers to keep up-to-date with the trends in the profession, and to be able to face the challenges in nursing practice (Adeniyi, 2010). However, the perception of nurse leaders toward leadership remains personal to the leaders as was indicated by Mcdikkoh (2010). Therefore, he emphasized on the need for nurse leaders to attend developmental programs and leadership seminars to more skills and knowledge that will change their mindset toward nurse leadership and be able to work toward organisational goals.

\section{Nurse Leadership Competencies}

For effective leadership that encompasses all aspects of nursing leadership, the adoption of the nursing leadership model of the Nursing Leadership Institute Competency Model (2003) is essential (Finkelman and Kenner, 2012). Therefore, nurse leadership competency will be discussed around this model: Personal mastery includes effective reflection, self-confidence, commitment, proactive in giving solutions to problems; interpersonal effectiveness includes leaders building an effective relationship with followers, collaborating and communicating effectively and managing conflicts; financial management includes effective management of budget, managing costs, staff budgeting and non-staff budgeting to meet patients' needs, preparing and presenting financial documents; human resource management includes collaborating to the recruitment of exceptional staff for effective performance; caring includes caring for patients, staff and self and applying emotional intelligence to meet with their basic needs; system thinking includes establishing new initiatives by being proactive in performances (Nursing Leadership Institute, 2003; Clark, 2009; Finkelman and Kenner, 2012). Figure summarizes the major nursing leadership competencies

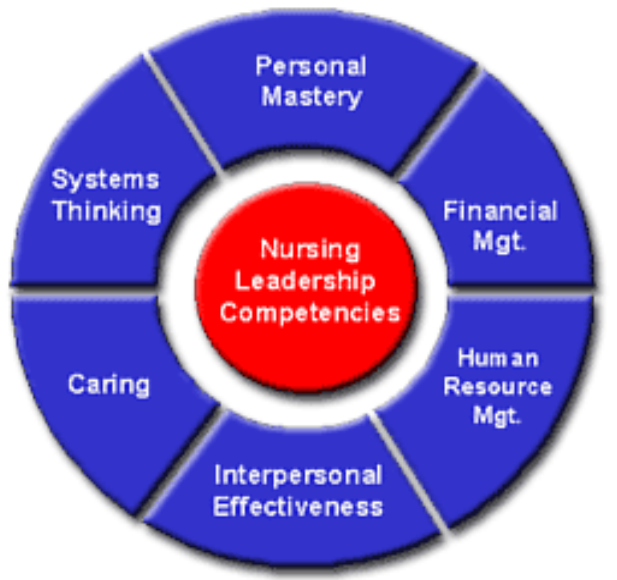

Figure 1: Nursing leadership competencies for effective healthcare outcomes. Source: Nursing Leadership Institute Competency Model (2003).

The competencies of nurse leaders are very critical in their day-to-day activities as long as they are in the leadership position to impact positively the growth and development of nursing practice (Abiodun, 2010). To 
enhance effective nursing leadership, all nurse leaders are then expected to navigate to the current strategies in general leadership, by applying the necessary skills and knowledge to ensure increased performance in all healthcare settings (Supamanee et al., 2011). Consequently, Stefl (2008) argued that the development of nursing competencies will help the nurse leader to face any future problem that might emanate in the process of leadership.

According to Bish et al. (2013), competency in nursing leadership is concerned with the skills in nursing practice; however, it also includes some other personal qualities which are inborn and research has also proven the essence of traits approach to leadership, therefore are very powerful. However, Daft (2008) enumerated some of the personal qualities as courage, humility, enthusiasm and integrity. Nevertheless, Bish et al. (2012) emphasized that being a competent leader does not primarily depend on personal qualities; thus developing a passion for your position as a nurse leader, connecting emotionally to your followers and engaging in lifelong learning gives a leader to carry out his/her duties effectively and gradually develops competency according to Benner (1984).

Building relationships among nurses and the interdisciplinary team is crucial in terms of developing competency in the nursing profession. Nurse leaders should not only focus on how the job is done, because the job may not be done without building strong relationships with the followers and the interdisciplinary teams (Daft, 2008). Again, for nurse leaders to be able to inspire, motivate, collaborate, coordinate and delegate effective, the nurse leader must have a good relationship with the workforce. Thus, nurse leaders are encouraged to build their competencies in terms of building a strong relationship with followers (Perry et al., 2009). Furthermore, Pencheon et al. (2008) and Eneh et al. (2012) added that nurse leaders empower nurses, creates an interesting workplace and makes nurses have job satisfaction by building a strong relationship and putting extra effort thereby improving performance (Eneh et al., 2012).

In addition, developing "collaborative and team-building skills" has been accorded high importance in ensuring competency among nurse leaders (Supamanee et al., 2011). This quality has been regarded as one of the trends in the $21^{\text {st }}$ century and should be adopted in all levels of nursing leadership. Primarily, nurse leaders should consider recent age as relationship age between the leaders and the followers because working cooperatively together as a team enhances the drive to achieve a common vision (O'Neil et al., 2008; Marquis and Huston, 2009). Conversely, in current healthcare practice, transforming nursing leadership is the talk of the day (Kelly, 2012). Hence, Kelly and Tazbir (2013) acclaimed transformational leadership in nursing to be the most desirable; therefore, nurse leaders are hereby encouraged to adjust to the present level of transformational nursing leadership to ensure growth and development in nursing practice.

On the other hand, emotional intelligence has also been seen as another approach to achieving transformation (Doody and Doody, 2012). Kelly (2012:12) regarded emotional intelligence as a leadership component defined as the "capacity for recognising your own feelings and those of others, for motivating yourself, and for managing emotions well in yourself and in your relationships. According to Kelly, to be able to maintain a good relationship in the workplace as a nurse leader, he or she needs to have empathy, self-awareness, motivation, self-regulation, and adequate social skills which are the social competencies in emotional intelligence. Furthermore, Moss (2005) and Kelly and Tazbir (2013) elaborated that emotional intelligent nurse leaders are able to communicate effectively and share vision, manage conflicts, and inspire followers to make their vision a reality. Figure 2 describes action centred leadership model.

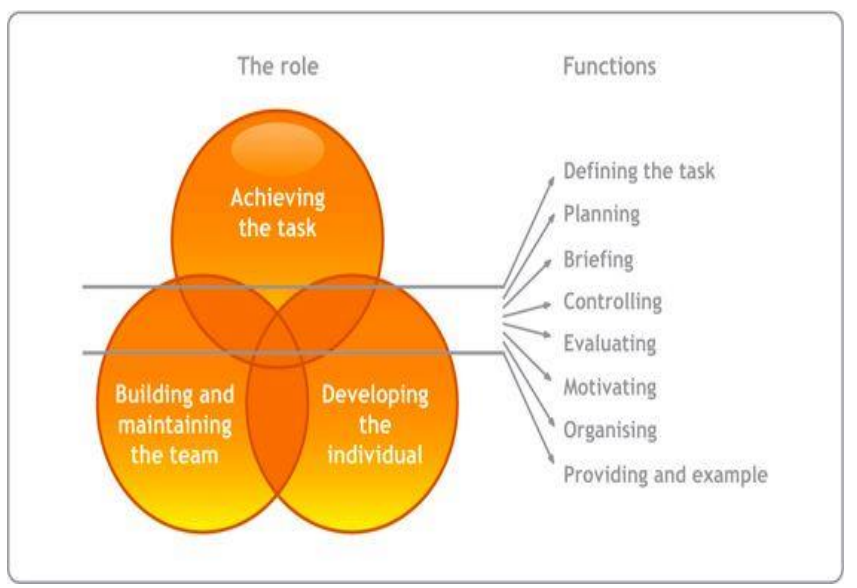

Figure 2: Action Centred Leadership Model. Source: John Adair (1987).

Furthermore, in achieving the nurse leadership competency model, it is essential to adopt John Adair (1987) Action Centred Leadership which includes achieving the task, building and maintaining the team and developing the individual. Significantly, Adair stated that leaders in performing their daily activities are expected to assist in achieving the task, ensure the team is strong by responding to the needs of the team and that of the individual. Therefore, to ensure effectiveness, nurse leaders need to ensure that none of the three elements must be ignored. Nevertheless, in the fulfilment of the three elements, Adair emphasized that some other functions such as defining the task, planning, briefing, controlling, evaluating, motivating, organising as well as setting an example has to be developed and performed to achieve the required success in the leadership process (Adair, 2011). However, in terms of the team, Belbin's Team Roles Model emphasized the need for leaders to pull the team together to be able to achieve a common goal, basically, the leader defines the tasks and the roles for the team members and facilitates how these tasks will be done effectively (Belbin, 2012)

\section{Cases of Nurse Leadership Scenarios and Impacts on Healthcare} Outcome/Nurses Perception

Eneh et al. (2012) argued that it is crucial that nursing staff give their opinion concerning nursing leadership; therefore, appraisals, feedback responses from nursing staff inform a favourable and better work environment in the healthcare sector. Leadership itself can bring neither positive nor negative impact on the organisation; the impact is regarded as the outcome of the leadership process. However, this has been attributed to the performance of the leader and how he applies his/her skills and knowledge (Murphy, 2009). However, researchers have also given proof that nursing leadership impacts effectively on the hospital wards (Grimm, 2010). On the contrary, Cavazotte et al. (2012). reported in his findings that leadership had little or no impact on healthcare outcomes; nevertheless, this was related to the fact that nurses were responsible and accountable enough and performing their duties without waiting for the leader's instructions; however, the leader also had her influence and facilitated how tasks were effectively carried out.

From a scoping review to identify contemporary issues among nursing leaders in a rural setting. Its essence was to create processes and structures that will enhance excellent and quality nursing care. From their findings; it was discovered that there was a need for effective nurse leaders due to the outlined relevance of a nurse leader to nursing practice. The ineffectiveness and inefficiency were noticed from the healthcare outcomes and it was recommended that the nurse leaders should be provided with the contemporary nurse leadership skills and strategies that will facilitate better nursing care thereby improving healthcare outcomes. Therefore, the impact of nursing leadership was noticed and emphasis was laid on improvement (Bish et al., 2012). Subsequently, PorterO'Gradyand Malloch, 2013) reported that nurse leaders need constant upto-date knowledge and skills to be able to face the challenges in the interdisciplinary healthcare practice to remain in the forefront of healthcare practice. 
Conversely, another exploratory research was carried out in 2011 , concerning the perceptions of staff nurses towards the application of leadership styles by nurse leaders and healthcare outcomes. However, it was found that was a strong correlation between the effective application of leadership styles by nurse leaders and healthcare outcomes. In fact, effective nurse leadership was seen as a predictor for excellence in nursing care thereby having a positive impact on healthcare outcomes (Casida and Parker, 2011). Furthermore, in the report of Bish et al. (2012) nurses' perceptions were seen to determine nursing care improvement. And it was found that nurses' perceptions showed that nursing leadership affects healthcare outcomes and patients' experience.

\section{Conclusion}

Conclusively, the effective application of leadership roles influences the workforce to achieve a shared value in the healthcare setting. Leadership has also been seen as a strategy that allows the leader to affect the followers and vice vasa, as an event of a transaction. However, effective nurse leadership has been seen as effectively applying leadership qualities, skills, knowledge and approaches such as traits and behaviour to achieve the desired outcome.

\section{References}

Abiodun, R. (2010). Leadership behaviour impact on employee's Loyalty, engagement and organisational performance. Bloomington. AuthorHouse.

Adair, J. (2011). Effective teambuilding: How to make a winning team. Oxford. Pan Books.

Adeniyi, M. A. (2010). Effective leadership management: An integration of styles, skills and character for today's CEOs. Bloomington. AuthorHouse.

Augustsson, G. and Boström, L. (2012). A theoretical Framework about Leadership perspectives and Leadership styles in the Didactic Room. International Journal of Human Resource Studies, Vol. 2, Iss. 4, Pp. 2162-3058.

Belbin, M. (2012). Team roles at work. Oxford. ButterworthHeinemann

Benner, P. (1984). From novice to expert, excellence and power in clinical nursing practice. Menlo Park. Addison-Wesley Publishing Company.

Bischoff, A. L. (2010). Leadership theories - Gandhi as leader. Norderstedt. Grin Verlag.

Bish, M., Kenny, A. and Nay, R. (2012). A scoping review identifying contemporary issues in rural nursing leadership. Journal of Nursing Scholarship, Vol. 44, Iss. 4, Pp. 411-417.

Bjarnason, D. and Ann, C. (2011). Moral leadership in nursing. Journal of Radiology Nursing, Vol. 30, Pp. 18-24.

Bolden, R., Hawkins, B., Gosling, J. and Taylor, S. (2011). Exploring leadership: Individual, organizational, and societal perspectives. Oxford. Oxford University Press.

Bondas, T. (2010). Nursing leadership from the perspective of clinical group supervision: A paradoxical practice. Journal of Nursing Management, Vol. 18, Iss. 4, Pp. 425-439.

Buscer, A., Sivertsen, B. and White, J. (2009). Nurses and Midwives: A Force for Health. Survey on the Situation of Nursing and Midwifery in the Member States of the European Region of the World Health Organization 2009 (online). WHO.

http://www.euro.who.int/_data/assets/pdf_file/0019/114157/ E93980.pdf, (Accessed 17/07/2013)

Casida, J. and Parker, J. (2011). Staff nurse perceptions of nurse manager leadership styles and outcomes. Journal of Nursing Management, Vol. 19, Pp. 478-486.

Cavazotte, F. Moreno, V. and Hickmann, M. (2012). Effects of leader intelligence, personality and emotional intelligence on transformational leadership and managerial performance. The Leadership Quarterly, Vol. 23, Pp. 3, Pp. 443-455.

Clark, C. (2009). Creative Nursing Leadership and Management. London. Jones and Bartlett Publishers.

Colbert, A. E., Judge, T. A., Choi, D. and Wang, G. (2012). Assessing the trait theory of leadership using self and observer ratings of personality: The mediating role of contributions to group success. The Leadership Quarterly, Vol. 23, Iss. 4, Pp. 670-685.
Comack, M. (2012). A journey of leadership: From bedside nurse to chief executive officer. Nursing Administration Quarterly, Vol. 36, Iss. 1, Pp. 29-34

Cummings, G. (2011). The call for leadership to influence patient outcomes. Nursing Leadership, Vol. 1, Pp. 22-25.

Cummings, G. G., MacGregor, T., Davey, M., Lee, H., Wong, C., Lo, E. and Stafford, E. (2009). Leadership styles and outcome patterns for the nursing workforce and work environment: A systematic review. International Journal of Nursing Studies, Vol. 47, Iss. 3, Pp. 363 385.

Cummings, G., MacGregor, T. and Davey, M. (2010). Leadership styles and outcome patterns for the nursing workforce and work environment: a systematic review. International Journal of Nursing Studies, Vol. 47, Pp. 363-385.

Daft, R. L. (2008). The Leadership Experience. $4^{\text {th }}$ Edition. Mason. Thompson Higher Education.

Dinh, J. E. and Lord, R. G. (2012). Implications of dispositional and process views of traits for individual difference research in leadership. The Leadership Quarterly, Vol. 23, Iss. 4, Pp. 651-669.

Doody, O. and Doody, C. (2012). Transformational leadership in nursing practice. British Journal of Nursing, Vol. 21. Iss. 20, Pp. 1212-1218.

Duyulu, S. and Kublay, G. (2011). Transformational leadership training programme for charge nurses. Journal of Advanced Nursing, Vol. 67, Iss. 3, Pp. 633-642.

Eneh, V. O., Vehvilainen-Julkunen, K. and Kvist, T. (2012). Nursing leadership practices as perceived by Finnish nursing staff: high ethics, less feedback and rewards. Journal of Nursing Management, Vol. 20, Pp. 159-169.

Ercetin, S. S. and Utin, E. U. E. (2012). Discussions about leadership: In different fields. Bloomington. iUniverse.

Finkelman, A. and Kenner, C. (2012). Professional Nursing Concepts: Competencies for Quality Leadership. New York. Jones and Bartlett Publishers.

Foster, D. T., Nollette, C., Nollette, F. P. and Goertzen, B. J. (2012). Emergency services leadership. Burlington. Jones and Bartlett Learning.

Giltinane, C. L. (2013). Leadership styles and theories. Nursing Standard, Vol. 27, Iss. 41, Pp. 35-39.

Greenberg, J. (2013). Organizational behaviour: the state of the science. New Jersey. Lawrence Erlbaum Associates.

Grimm, J. W. (2010). Effective leadership: making the difference.Journal of Emergency Nursing, Vol. 36, Vol. 1, Pp. 7477.

Halpern, D. F. and Cheung, F. M. (2011). Women at the Top: Powerful Leaders Tell Us How to Combine Work and Family. Oxford. Blackwell Publishing.

Hersey, P., Blanchard, K. and Johnson, D. (2008). Management of organisational behaviour: Leading human resources. 9th Edition. Englewood Cliffs. Prentice Hall.

Iqbal, T. (2011). The impact of leadership styles on organizational effectiveness. Germany. Grin Verlag.

Kelly, P. (2012). Nursing leadership and management. $3^{\text {rd }}$ Edition. New York. Cengage Learning.

Kelly, P. (2013). Essentials of nursing leadership and management. 3rd Edition. New York. Delmar Health Care.

Kelly, P. and Tazbir, J. (2013). Essentials of nursing leadership and management. 3rd Edition. London. Delmar Health Care.

Khan, H., Rehmat, M., Butt, T.H. et al. Impact of transformational leadership on work performance, burnout and social loafing: a mediation model. Futur Bus J 6, 40 (2020). https://doi.org/10.1186/s43093-020-00043-8.

Komives, S. R., Lucas, N., McMahon, T. R. (2013). Exploring leadership: For college students who want to make a difference. $3^{\text {rd }}$ Edition. San Francisco. Jossey-Bass.

Lussier, R. N. and Achua, C. F. (2013). Leadership: Theory, application, skill development. 5th Edition. Cincinnati. South-Western College Publishing.

Marquis, B. and Huston, C. (2009). Leadership roles and management functions in nursing: Theory and application. 6th Edition. Philadelphia. Williams and Wilkins. 
Mcdikkoh, D. M. N. (2010). The Nigerian health system's debacle and failure. New York. Xlibris Corporation.

Mendenhall, M. E.,Osland, J., Bird, A., Oddou, G. R., Maznevski, M. L., Stevens, M. and Stahl, G. K. (2013). Global leadership 2e: Research, practice, and development. New York. Routledge.

Misener, R. M., MacLeod, M. L. P., Banks, K., Morton, A. M., Vogt, C., and Bentham, D. (2008). There's rural and then there's rural: Advice from nurses providing primary healthcare in northern remote communities. Nursing Leadership, Vol. 21, Iss. 3, Pp. 54-63.

Moss, M. T. (2005). The emotional intelligent nurse leader. San Francisco. Jossey-Bass.

Murphy, J. (2009). Role of clinical nurse leadership in improving patient care. Nursing Management, Vol. 16, Iss. 8, Pp. 26-28.

Newton, S. (2009). New directions in leadership. Construction Innovation, Vol. 9, Iss. 2, Pp. 129-132.

Northouse, P. G. (2010). Leadership: Theory and Practice. $5^{\text {th }}$ Edition. Sage Publications,

Northouse, P. G. (2012). Leadership: Theory and Practice. New York. Sage.

Nursing Leadership Institute. (2003). The nursing leadership institute competency model. http://www.fau.edu/nli/model2.pdf (Accessed $19 / 07 / 2013)$

O’Neil, E., Morjikian, R. L. and Cherner, D. (2008). Developing nurse leaders: An overview of trends and programs. Journal of Nursing Administration, Vol. 38, Iss. 4, Pp. 178-183.

Paliadelis, P. S., Parmenter, G., Parker, V., Giles, M., and Higgins, I. (2012). The challenges confronting clinicians in rural acute care settings: A participatory research project. International Electronic Journal of Rural and Remote Health Research, Education Practice and Policy. http://www.rrh.org.au/publishedarticles/article print 2017.pdf (Accessed 18/07/2013).

Passmore, J. (2010). Leadership Coaching: Working with Leaders to Develop Elite Performance. London. Kogan Page Limited.
Perry S., D., and Gaffney, V. J. (2009). Creative practicum leadership experiences in rural settings. Nurse Educator, Vol. 34, Iss. 1, Pp. 38-42.

Porter-O'Grady, T. and Malloch, K. (2012). Leadership \& Management in Nursing: Advanced Nursing Career. Burlington. Jones and Bartlett Learning.

Porter-O'Grady, T. and Malloch, K. (2013). Leadership and management in nursing: Advanced nursing career. Burlington. Jones and Bartlett learning.

Randall, D., Rouncefield, M. and Graham, C. (2011). Leadership in Post-Compulsory Education. London. Continuum International Publishing Group.

Stanfield, A. W. (2009). Defining Effective Leadership: Lead in Whatever You Do. Oklahoma. Tate Publishing and Enterprises.

Stefl, M. E. (2008). Common Competencies for All Healthcare Managers: The Healthcare Leadership Alliance Model. Journal of Healthcare Management, Vol. 53, Iss. 6, Pp. 360-374.

Supamanee, T., Krairiksh, M., Singhakhumfu, L. and Turale, S. (2011). Preliminary clinical nursing leadership competency model: a qualitative study from Thailand. Vol. 13, Iss. 4, Pp. 433-439.

Todnem, R. and Burnes, B. (2013). Organizational change, leadership and ethics: Leading organizations towards sustainability. New York. Routledge.

Wang, X., Chontawan, R. and Nantsupawas, R. (2012). Transformational leadership: effect on the job satisfaction of Registered Nurses in a hospital in China.Journal of Advanced Nursing 68(2), 444-451.

Winkler, I. (2011). Contemporary leadership theories: Enhancing the understanding of the complexity, subjectivity and dynamic of leadership. London. Springer.

Wong, C. and Cummings, G. (2009). Authentic leadership: A new theory for nursing or back to basis. Journal of Health Organisation and Management, Vol. 15, Pp. 508-521.

- Thank you for publishing with us. 